\title{
Pelatihan Pembuatan Filter Air Sederhana Skala Rumah Tangga di Kelurahan Gambut
}

\author{
Norsita Agustina ${ }^{1}$, Chandra $^{2}$, Zuhrupal Hadi $^{3}$, Ahmad Fauzan $^{4}$, Eddy Rahman $^{5}$ \\ ${ }^{1-5}$ Fakultas Kesehatan Masyarakat, Universitas Islam Kalimantan (UNISKA) MAB Banjarmasin \\ Email: norsita.agustina@gmail.com
}

Submitted : 11/10/2021

Accepted: 08/01/2022

Published: 28/01/2022

\begin{abstract}
Clean water is one of the basic needs for human life. Making simple raw water treatment equipment using a filtration system is expected to help the community to process dirty water into raw water on the scale of household needs. Poor water quality will affect the health of existing residents. There is a need for innovation in the manufacture of water filters in order to improve the quality of water for daily needs so that it becomes a more useful product or material. The method used in achieving the goal is to provide training in making simple water filters. The right method used for processing turbid water from household dug wells into clean water in an area is to use the multilevel filter method. This filtering process is to remove suspended solids or the separation process between solids/colloids and liquid solids. The conclusion in this activity is that the training on making simple water filters can be accepted by local residents to get clean and not cloudy water. It is hoped that with this activity there will be more efforts and willingness from the community to improve the quality of healthy life by paying attention to aspects of the availability and use of clean water
\end{abstract}

Keywords: household, simple, training, water filter

\begin{abstract}
Abstrak
Air bersih merupakan salah satu kebutuhan pokok bagi kehidupan manusia. Pembuatan alat pengolahan air baku sederhana menggunakan sistem filtrasi diharapkan dapat membantu masyarakat untuk mengolah air kotor menjadi air baku dalam skala kebutuhan rumah tangga. Kualitas air yang kurang baik akan mempengaruhi kesehatan warga yang ada. Perlu adanya inovasi pembuatan filter air agar dapt meningkatkan kualitas air untuk kebutuhan sehari-hari sehingga menjadi produk atau bahan yang lebih bermanfaat. Metode yang digunakan dalam pencapaian tujuan dengan memberikan pelatihan pembuatan filter air sederhana. Pada metode yang tepat digunakan untuk pengolahan air keruh dari sumur gali rumah tangga menjadi air bersih pada suatu daerah adalah dengan menggunakan metode saringan bertingkat. Proses penyaringan ini untuk menghilangkan zat padat tersuspensi atau proses pemisahan antara padatan/koloid dengan cairan bahan padatan. Kesimpulan dalam kegiatan ini adalah pelatihan pembuatan filter air sederhana dapat diterima oleh warga setempat untuk mendapatkan air yang bersih dan tidak keruh. Diharapkan dengan kegiatan ini ada upaya dan kemauan lebih dari masyarakat untuk meningkatkan kualitas hidup sehat dengan memperhatikan aspek ketersediaan dan penggunaan air bersih.
\end{abstract}

Kata Kunci : filter air, pelatihan, rumah tangga, sederhana,

\section{PENDAHULUAN}

Air merupakan salah satu penyebab masalah kesehatan. Kesehatan merupakan hal yang sangat berharga bagi manusia. Menjaga kesehatan dapat dimulai dengan menjaga kesehatan lingkungan (Sastrawijaya, Tresna, 1991). Permasalahan yang sangat umum ditemukan di Kelurahan
Gambut adalah permasalahan sanitasi, salah satu yang paling menonjol adalah mengenai air bersih. Air bersih yang digunakan oleh masyarakat Kelurahan Gambut, khususnya warga sekitar Kelurahan Gambut kualitasnya masih dalam kategori kurang layak, air tersebut memiliki kualitas air dengan kekeruhan yang tinggi serta terdapat 
partikel-partikel yang terbawa dari tanah lempung sehingga harus melalui proses pengolahan apabila ingin dikonsumsi atau digunakan untuk kebutuhan sehari-hari.

Kualitas air yang kurang baik akan mempengaruhi kesehatan warga yang ada.. Perlu adanya inovasi pembuatan filter air agar dapt meningkatkan kualitas air untuk kebutuhan sehari-hari sehingga menjadi produk atau bahan yang lebih bermanfaat.

Dalam hal ini pengusul bersama anggota melakukan penelitian sebelumnya ternyata warga disana mengkonsumsi air yang tidak layak konsumsi sehingga banyaknya warga yang mengalami gangguan kesehatan baik bagi pencernaan maupun kesehatan pada kulit. Perlu adanya inovasi pembuatan filter air sederhana degan berskala rumah tangga agar dapat dipergunakan oleh warga dan agar menjadi produk atau bahan yang lebih bermanfaat.

\section{TARGET DAN LUARAN}

Terjadinya peningkatan pengetahuan dan keterampilan oleh ibu lurah di Kecamatan Gambut terhadap wawasan tentang air bersih dan pembuatan serta penggunaan alat filter. Diharapkan dengan kegiatan ini ada upaya dan kemauan lebih dari masyarakat untuk meningkatkan kualitas hidup sehat dengan memperhatikan aspek ketersediaan dan penggunaan air bersih air sederhana untuk keperluan seharihari.

\section{METODE PELAKSANAAN}

Program kegiatan dilakukan dengan menggunakan metode observasi lapangan dan sosialisasi secara langsung. Metode ini digunakan untuk mengetahui dan menganalisa sebuah permasalahan yang ada di suatu wilayah dan mencari solusi yang tepat untuk mengatasi sebuah masalah yang ada.

Observasi lapangan dilakukan dengan menggunakan pengamatan langsung terhadap kondisi air tanah yang ada di masyarakat lingkungan Kelurahan Gambut.
Observasi ini didukung dengan kegiatan wawancara kepada beberapa masyarakat kelurahan untuk mengetahui kondisi air tanah pada sumur warga dan bagaimana penggunaan air tanah dalam memenuhi kebutuhan sehari-hari masyarakat. Studi litelatur juga diperlukan guna memperdalam pengolahan data sehingga data menjadi layak didsajikan dalam bentuk dokumen yang sistematis.

Salah satu metode yang tepat digunakan untuk pengolahan air keruh dari sumur gali rumah tangga menjadi air bersih pada suatu daerah adalah dengan menggunakan metode saringan bertingkat. Proses penyaringan adalah proses untuk menghilangkan zat padat tersuspensi atau proses pemisahan antara padatan/koloid dengan cairan bahan padatan. Tahapan yang digunakan meliputi tahapan awal

a. Pemindahan dan penampungan air sumur ke wadah air;

b. Pengendapan air;

c. Pembuangan endapan;

d. Penurunan kadar logam berat dengan aerasi difiltrasi (penyaringan) (Wahyudi dkk, 2014:35).

Alat yang digunakan dalam pelaksanaan program kegiatan ini adalah peralatan untuk membuat alat filter, bahan filter, kamera sebagai alat dokumentasi, Alat tulis. . Pelaksanaan kegiatan dilaksanakan dengan penyuluhan, sosialisasi dan demonstrasi/pelatihan masyarakat untuk memperoleh wawasan tentang air bersih dan pembuatan serta penggunaan alat filter. Target masyarakat untuk penerapan alat filter secara umum adalah masyarakat Kelurahan Gambut, dan secara khusus adalah masyarakat di Kelurahan Gambut.

Kegiatan yang selanjutnya adalah sosialisasi pembuatan filter, hal ini ditujukan agar warga Kelurahan Gambut mampu untuk membuat filter air sederhana skala rumah tangga. 


\section{HASIL DAN PEMBAHASAN}

Pembuatan filter air sederhana dikerjakan dalam beberapa tahap, setiap tahapan yang dikerjakan saling mendukung tahapan lainnya, tahapan yang dikerjakan sebagai berikut :

a. Tahap Pra Pelaksanaan

Tahap pra pelaksanaan kegiatan dilakukan untuk memperoleh data yang dapat diolah untuk mendapatkan solusi penyelesaian masalah yang tepat, adapun tahapan yang dilakukan adalah sebagai berikut :

Observasi Wilayah

Observasi wilayah secara umum dilakukan di Kelurahan Gambut. Observasi bertujuan untuk menentukan karakteristik air yang ada di Kelurahan Gambut sehingga dapat diketahui parameter pencemar dan teknik pengolahan yang sesuai. Kegiatan pengambilan air telah dilakukan saat pelaksana melakukan penelitian pada bulan Maret 2020. Observasi ini dilakukan untuk memperoleh data awal yang digunakan untuk mengidentifikasi variasi karakteristik air yang ada di masyarakat.

Dari hasil observasi lapangan diperoleh data mengenai kondisi kualitas air di lingkungan di Kelurahan Gambut. Kualitas air yang ada ialah air dengan kualitas yang dibawah ambang batas parameter yang ditetapkan.

Pengumpulan data dilanjutkan dengan mewawancarai tokoh masyarakat dan beberapa perangkat desa sebagai masyarakat Kelurahan Gambut. Dari hasil wawancara diperoleh data statistik kependudukan Kelurahan Gambut hamper seluruh warga Kelurahan Gambut menggunakan air yang berasal dari sumber air, air tersebut digunakan untuk kegiatan sehari-hari mulai dari mencuci, mandi, dan memasak.
Setelah melakukan observasi lapangan dapat tarik kesimpulan mengenai arah pengolahan air di Kelurahan Gambut. Pengolahan air sederhana yang dipilih adalah filter air. Filter air menggunakan batuan alamiah sebagai media saring dengan alasan harga yang terjangkau dan pembuatan serta perawatan alat terbilang mudah. Pemilihan material batuan alamiah sebagai material saring didasarkan pada penurunan kualitas air yang ditinjau dari parameter fisik seperti bau, warna dan rasa.

b. Pelaksanaan/Operasional

Pelaksanaan program kegiatan pembuatan alat filter dibagi kedalam beberapa pelakasanaan kegiatan yang meliputi:

PembuatanAlat Filter

Pembuatan media filter dilakukan untuk mengidentifikasi bahan apa saja yang dapat digunakan sebagai media filter, pemilihan bahan sangat mempengaruhi tingkat efektifitas dari filter tersebut, bahan yang dipilih adalah batu zeolit, karbon aktif, kerikil/pasir silika, dan, sabut kelapa dan kapas. Selain pemilihan bahan, pemilihan wadah juga penting dilakukan. Wadah yang digunakan tergantung pada tujuan penggunaan filter tersebut, wadah botol plastik untuk skala uji coba, botol bekas berukuran 1,5 L untuk skala rumah.. Setelah pembuatan filter air selesai dibuat selanjutnya bahan yang sudah didapat disusun menjadi satu ke dalam wadah yang sudah disiapkan. Dimana masing-masing bahan memiliki fungsi sebagai berikut :

1. Pasir Silika : Di dalam system penjernih air sederhana ini, Fungsi pasir silika adalah untuk menyaring kotoran berukuran kecil yang terbawa bersama air.

2. Pasir Aktif berfungsi untuk menghilangkan kandungan besi 
(Fe), menghilangkan sedikit Mangan (Mn2+) dan warna kuning pada air tanah atau sumber air lainnya. Fe dan Mn dalam air biasanya diturunkan dengan cara aerasi air pada $\mathrm{pH}>7$ sehingga kedua logam ini mengendap sebagai oksidanya.

3. Batu Zeolit/Batu kerikil : Di dalam system penjernih air sederhana ini, Fungsi zeolit/batu kerikil adalah untuk menghilangkan kandungan $\mathrm{Ca} 2+$ dan $\mathrm{Mg} 2+$. Air yang mengandung $\mathrm{Ca} 2+$ dan $\mathrm{Mg} 2+$ berlebih menyebabkan kualitas air menurun, atau dengan bahasa sederhana biasa disebut dengan "Air Sadah". Air sadah biasanya berbau dan rasanya seperti kapur.

4. Karbon Aktif : Di dalam system penjernih air sederhana ini, Karbon aktif berfungsi untuk menghilangkan bau, dan rasa pada air. Selain itu karbon aktif juga berfungsi untuk menyerap kaporit atau chlorine pada air. Menurut Pettijhon (1987) dalam Handarsari (2017) bahwa pasir dapat dikelompokkan menjadi tiga kategori. Antara lain pasir terigen pasir (terrigeneous sand), karbonat (carbonate sand) dan pasir piroklastik (pyroclastic sand). Arang merupakan suatu padatan berpori yang memiliki komponen unsur berupa karbon bebas dengan ikatan kovalen. Permukaan arang aktif bersifat non polar.

c. Pelatihan Pembuatan Alat Filter

Pengujian alat filter dilengkapi dengan sosialisasi dan pelatihan pembuatan alat kepada masyarakat Kelurahan Gambut. Pelatihan pembuatan filter air sederhana ini dilakukan dengan cara mengundang perwakilan dari Ibu Lurah yang ada di Kelurahan Gambut yang dilaksanakan pada Hari Sabtu, 13 Maret 2021 di
Rumah Ibu Lurah Gambut yang dihadiri 10 Ibu lurah yang ada di Wilayah Kerja Kelurahan Gambut. Kegiatan ini bertujuan agar masyarakat mendapat pengetahuan dan pemahaman cara mengkonsumsi air serta bagaimana cara pembuatan alat filter sederhana dengan skala rumah tangga Masyarakat juga mendapat informasi mengenai hasil uji alat filter dan bagaimana cara perawatan alat filter.

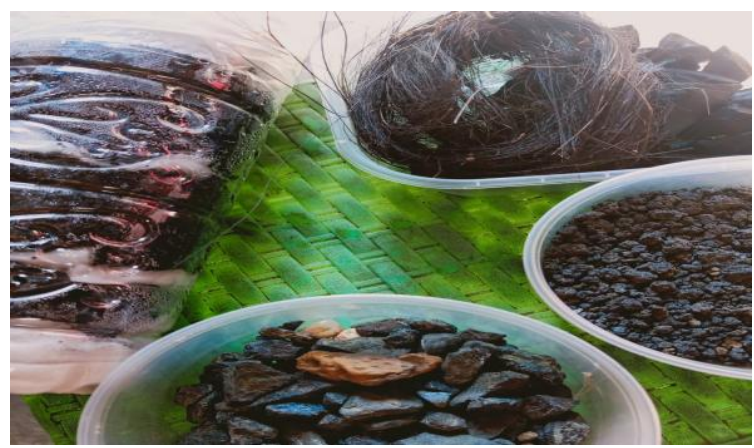

Gambar 1.

Bahan dan Alat Pembuatan Filter Air Sederhana Skala Rumah Tangga

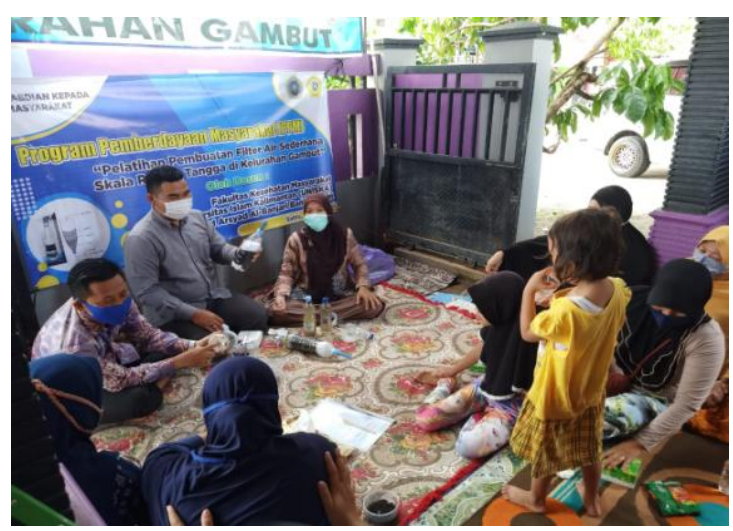

Gambar 2

Pelakasanaan Pelatihan Pembuatan Filter Air Sederhana Skala Rumah Tangga 


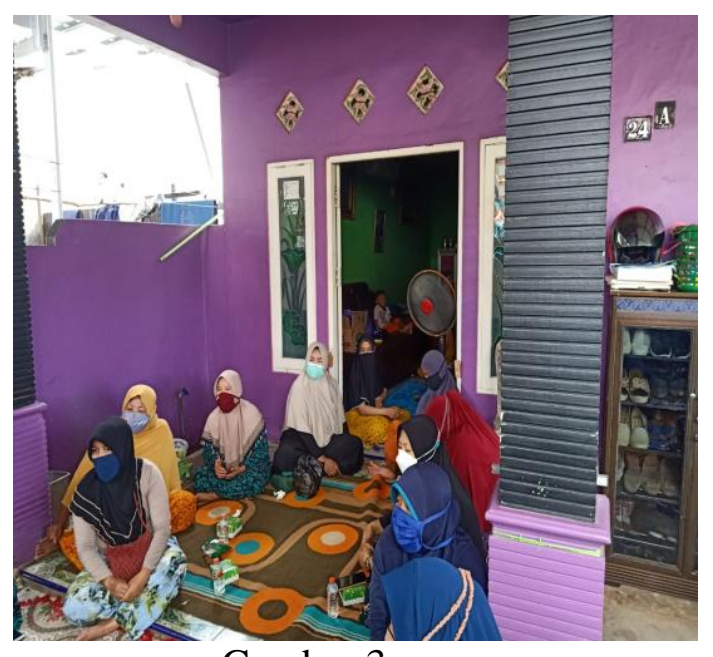

Gambar 3

Para Ibu Lurah yang sedang memperhatikan Praktik Pembuatan Filter Air Sederhana Skala Rumah Tangga

Dalam pelaksanaan kegiatan pelatihan pembuatan alat filter tim pelaksana membawakan materi dengan menggunakan media filter air. Di akhir kegiatan diadakan diskusi interaktif sehingga masyarkat dengan dapat bertukar pikiran dengan tim pelaksana tentang permasalahan air bersih di Kelurahan Gambut serta solusi yang ditawarkan. Pada sesi ini, masyakarat juga menggali informasi mengenai cara, teknik pembuatan, bahan yang digunakan serta perkiraan biaya pembuatan alat filter. Diharapkan dengan kegiatan ini ada upaya dan kemauan lebih dari masyarakat untuk meningkatkan kualitas hidup sehat dengan memperhatikan aspek ketersediaan dan penggunaan air bersih.

\section{KESIMPULAN DAN SARAN}

\section{Kesimpulan}

Salah satu permasalahan sanitasi yang dihadapi masyarakat Kelurahan Gambut adalah air bersih yang digunkan sehari-hari masih kurang layak ditandai dengan sifat air yang keruh. Hal tersebut dapat ditanggulangi dengan alat filter yang mampu menjadikan air lebih jernih. Filter yang dibuat adalah filter sederhana sebagai contoh untuk dipublikasikan kemasyrakat kelurahan Gambut dengan tujuan masyarakat kelurahan Gambut mampu menyelesaikan permasalahan air bersih yang bersifat keruh secara mandiri.

\section{Saran}

Untuk memaksimalkan kinerja alat filter sangat perlu dilakukan uji labolatorium,karena uji labolatorium sangat membantu dalam memonitoring bahanbahan dan kualitas air yang di gunakan. Hal ini sangat membantu dalam pengambilan keputusan untuk tahap selanjutnya dalam pembuatan filter sederhana.

\section{UCAPAN TERIMAKASIH}

Penulis mengucapkan terimakasih kepada LPPM Universitas Islam Kalimantan (MAB) Banjarmasin,seluruh Ibu Lurah yang ada di Kecamatan Gambut dan serta enumerator dalam pelaksanaan kegiatan pengabdian masyarakat.

\section{DAFTAR PUSTAKA}

A.Tresna Sastrawijaya, Pencemaran Lingkungan Hidup, Rineke Cipta, Jakarta,1991.

Herlambang, Arie, dkk. 1996. Database Air Tanah Jakarta, Studi Opstimisasi Pengelolaan Air Tanah : Jakarta, Dit P.S., Dep. Analisa Sistem, BPPT. Jakarta

Handarsari, Erma dkk. 2017. Deseminasi:

Pembuatan Air Bersih Dengan

Memanfaatkan Air Hujan Melalui

Penyaring Pipa Bersusun Berbasis

Adsorben Alami. Prosiding Seminar

Nasional Publikasi Hasil-Hasil

Penelitian dan Pnegabdian 
Jurnal Abdimas Kesehatan (JAK) Vol 4, No. 1, Januari, 2022

DOI : $10.36565 / j a k . v 4 i 1.276$

p-ISSN: 2655-9266

e-ISSN: 2655-9218

Masyarakat. Universitas

Adsorbsi Karbon Aktif. Tesis

Muhamadiyah Semarang: Semarang

Munir, M. 1996. Tanah-Tanah Utama

Program Pascasarjana. Universitas

Indonesia. Pustaka Jaya. Jakarta.

Inonesia, Jakarta.

UNICEF Indonesia. AIR BERSIH,

Setyaningsih, H. 1995. Pengolahan Limbah

SANITASI DAN KEBERSIHAN.

Batik Dalam Proses Kimia Dan

Ringkasan Kajian. Oktober 2012:1. 